\title{
Morphology of the Dorsal Lingual Papillae in the Bush Dog (Speothos venaticus)
}

\author{
By \\ Shoichi EMURA*, Akira TAMADA*, Daisuke HAYAKAWA**, Huayue CHEN**
and Shizuko SHOUMURA $* *$ \\ *College of Medical Sciences, Gifu University, Gifu, Japan \\ **Department of Anatomy, Gifu University School of Medicine, Gifu, Japan
}

- Received for Publication, April 20, 2000 -

\begin{abstract}
Key Words: Bush dog, Tongue, Lingual papillae, SEM
Summary: The dorsal lingual surface of a bush dog (Speothos venaticus) was examined by scanning electron microscopy (SEM). The tongue was about $7 \mathrm{~cm}$ in length. Filiform, fungiform and vallate papillae were found. The filiform papillae were distributed over the entire dorsal surface of the tongue. Each filiform papillae on the apical surface of the tongue had several conical processes, in the midportion were larger than those on the apex in size. In the region of the vallate papillae, the filiform papillae had not the conical processes and more larger than those on the midportion of the tongue. The fungiform papillae were present rounded bodies and more densely distributed on the tip of the ligual apex. There were 5 vallate papillae on both sides. The vallate papillae were located on both sides of the posterior end of the lingual body. Each papilla was surrounded by a groove and a crescent pad. In the dorsal surfaces of the papillae, small conical papillae were observed.
\end{abstract}

Much work has been published on the threedimentional structures of the lingual surfaces in various animals. In the order Carnivora, there have been some SEM studies of the tongues of cat (Boshell et al., 1982; Ojima et al., 1997), dog (Iwasaki and Sakata, 1985), mongoose (Iwasaki et al., 1987) and japanese weasel (Furubayashi et al., 1989). Furthermore, the tongues of dog (Iwasaki and Miyata, 1989) and mongoose (Iwasaki and Miyata, 1990) have been studied by transmission electron microscopy (TEM). Such studies reveal variations in morphology and distribution of papillae on the dorsal lingual surface among animal species.

However, there is no study on SEM studies of the tongue of the bush dog. The purpose of this study is, therefore, to examine three-dimentionally the dorsal lingual surface of the bush dog, in order to compare the results with those previous reports in other order Carnivora.

\section{Materials and Methods}

Tongue of a female bush dog (7-year-old) of the order Carnivora was used in this study. The tongue was fixed in $10 \%$ formalin. Small blocks containing papillae were cut with a razor blade, postfixed with $1 \%$ osmium tetroxide for $2 \mathrm{~h}$. Thereafter, the specimens were dehydrated through graded series of acetone, critical-point-dried and plasma-coated with $\mathrm{OsO}_{4}$ before being examined under SEM (Hitachi S-3500N) at an accelerating voltage of $10 \mathrm{kV}$.

\section{Results}

The tongue is about $7 \mathrm{~cm}$ in length. The filiform papillae are distributed over the entire dorsal surface of the tongue. Each filiform papillae on the apical surface of the tongue have several conical processes. (Fig. 1). The filiform papillae in the midportion of the dorsum of the tongue are larger than those on the apex of the tongue in size (Fig. 2). In the region of the vallate papillae, the filiform papillae have not the conical processes and more larger than those on the midportion of the tongue (Fig. 3). The fungiform papillae are present rounded bodies and more densely distributed on the tip of the lingual apex (Figs. 1,2). There are 5 vallate papillae on both sides. The vallate papillae 
are located on both sides of the posterior end of the lingual body. Each papilla is surrounded by a groove and a crescent pad. In the dorsal surfaces of the papillae, small conical papillae are observed (Fig. 3).

\section{Dicussion}

Boshell et al. (1982) reported that the filiform papillae on the tip of the tongue of the cat were short and exhibited several conical processes from the base of each papilla, in the midportion consisted of a large mound with a single sharp spinous process projecting posteriorly and in the region of the vallate papillae were shorter and more conical than those on the midportion. Iwasaki and Sakata (1985) reported that each filiform papilla on the apical surface of the tongue of the dog had a domeshaped bulge in the baso-frontal areas, some conical twigs were arranged semicircularly from the back of the bulge, on the middle area the bulge of the filiform papillae became gradually smaller and flatter, and only the central twig became gradually larger and the other twigs became smaller. Iwasaki et al. (1987) indicated that in the mongoose the form of filiform papillae changed gradually from the lingual apex to the posterior part of the lingual body.

In the present study, each filiform papilla on the apical surface of the tongue had several conical processes, in the midportion were larger than those on the tip in size. In the region of the vallate papillae, the filiform papillae had not the conical processes and more larger. These findings are similar to the observations of the dog (Iwasaki and Sakata, 1985).

Much work has been published on the threedimentional structure of the vallate papilae in the mammalian tongue. Several studies indicated that the vallate papillae showed a flattened oval shape and the papillae were surrounded by a groove and pad (Krause and Cutts, 1982; Chamorro et al., 1986; Qayyum et al., 1988; Chunhabundit et al., 1992; Agungpriyono et al., 1995; Atoji et al., 1998). The vallate papillae of the cat, dog or flying squirrel were encircled by the filiform papillae in the posterior body (Boshell et al., 1982; Iwasaki and Sakata, 1985; Emura et al., 1999). Equine vallate papilae were composed by a primary papilla which was divided into several secondary papillae by intermediate grooves (Chamorro et al., 1986). Sometimes, in bovine vallate papillae twin papillae were surrounded only by a primary papillary groove (Chamorro et al., 1986).

In this study, the vallate papillae were located on both sides of the posterior end of the lingual body. Each papilla was surrounded by a groove and crescent pad, and in the dorsal surfaces of the papillae small conical papillae were observed. However, there is no report of the small papillae in the dorsal surface of the vallate papillae.

\section{Acknowledgements}

The authors would like to express their most sincere thanks to staffs of Higashiyama Zoo \& Botanical Gardens for their assistance in preparing the material for this study.

\section{References}

1) Agungpriyono S, Yamada J, Kitamura N, Nisa C, Sigit K and Yamamoto Y. Morphology of the dorsal lingual papillae in the lesser mouse deer, Tragulus javanicus. J Anat 1995; 187:635-640.

2) Atoji Y, Yamamoto $Y$ and Suzuki Y. Morphology of the tongue of a male formosan serow (Capricornis crispus swinhoei). Anat Histol Embryol 1998; 27:17-19.

3) Boshell JL, Wilborn WH and Singh BB. Filiform papillae of cat tongue. Acta Anat 1982; 114:97-105.

4) Chamorro CA, de Paz P, Snadval J and Fernandez JG. Comparative scanning electron-microscopic study of the lingual papillae in two species of domestic mammals (Equus caballus and Bos taurus). I. Gustatory papillae. Acta Anat 1986; 125:83-87.

5) Chunhabundit P, Thongpila and Somana R. SEM study on the dorsal lingual surface of the common tree shrew, Tupaia glis. Acta Anat 1992; 143:253-257.

6) Emura S, Tamada A, Hayakawa D, Chen H, Jamali M, Taguchi $\mathrm{H}$ and Shoumura S. SEM study on the dorsal lingual surface of the flying squirrel, Petaurista Leucogenys. Ann Anat 1999; 181:495-498.

7) Furubayashi $R$, Sato $E$ and Ishibashi $T$. Histological pattern of the tongue in the Japanese weasels, Mustela itatsi, with special reference to the morphology and distribution of papillae, taste buds and lingual glands. Acta Anat Nippon $1989 ; 64: 210-214$.

8) Iwasaki $S$ and Miyata $K$. Fine structure of the filiform papilla of beagle dogs, J Moroph 1989; 201:235-242.

9) Iwasaki $S$ and Miyata $K$. Fine structure of the dorsal epithelium of the mongoose tongue. J Anat 1990; 172:201212.

10) Iwasaki S, Miyata $K$ and Kobayashi K. Comparative studies of the dorsal surface of the tongue in three mammalian species by scanning electron microscopy. Acta Anat 1987; 128:140-146.

11) Iwasaki $S$ and Sakata K. Scanning electron microscopy of the lingual dorsal surface of the beagle dog. Okajimas Folia Anat Jpn 1985; 62:1-14.

12) Krause WJ and Cutts JH. Morphological observations on the papillae of the opossum tongue. Acta Anat 1982; 113:159-168.

13) Ojima K, Takeda M, Matsumoto $S$ and Nakanishi I. An investigation into the distributive pattern, classification and functional role of the conical papillae on the posterodorsal surface of the cat tongue using SEM. Ann Anat 1997; 
179:505-510

14) Qayyum MA, Fatani JA and Mohajir AM. Scanning electron microscopic study of the lingual papillae of the one humped camel, Camelus dromedarius. J Anat 1988; 160:21-26.

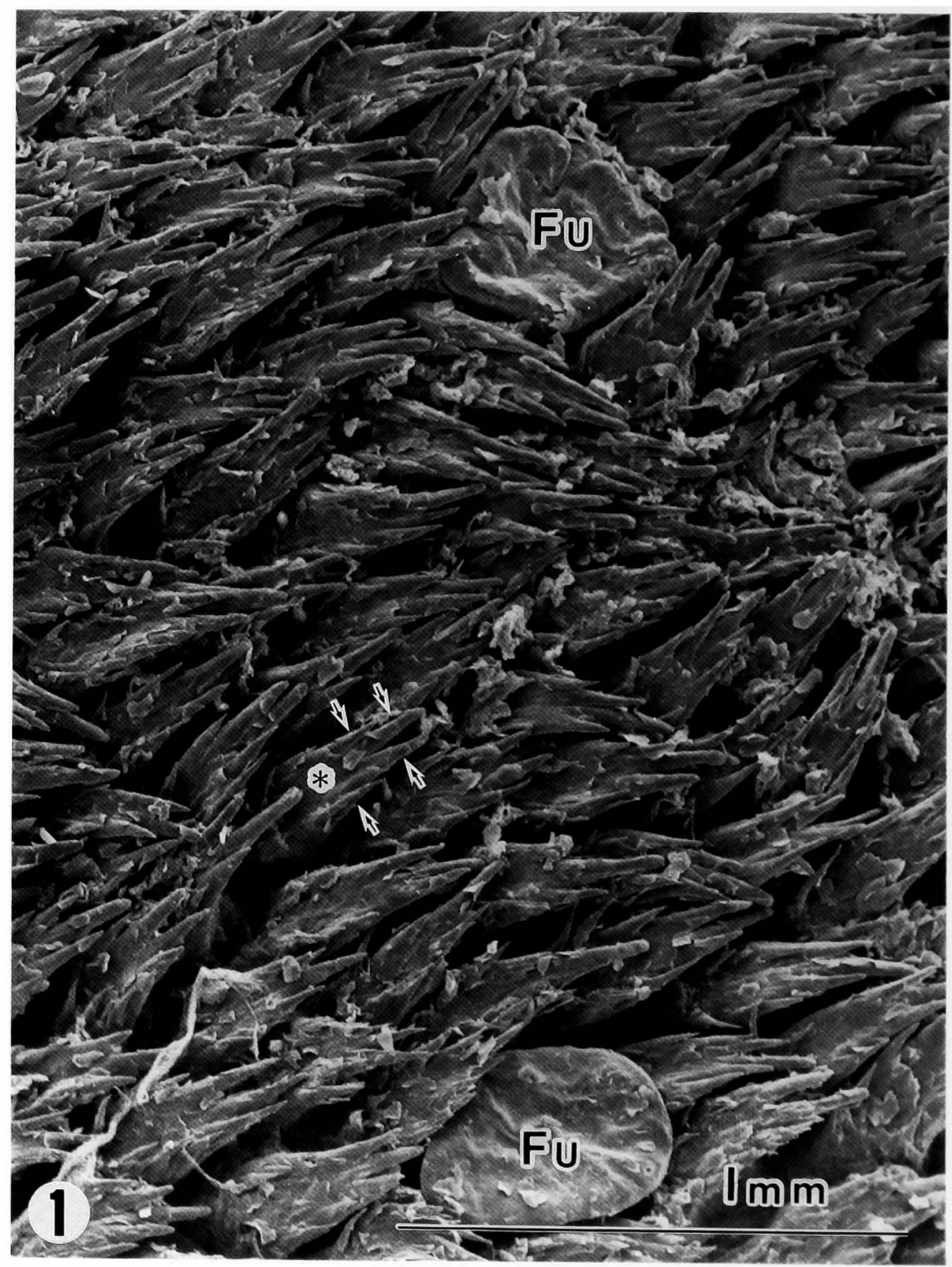

\section{Explanation of Figures}

\section{Plate I}

Fig. 1. Dorsal surface of the lingual apex. The filiform papilla $(*)$ has several conical processes (arrows). Fu=fungiform papillae. 
Plate II

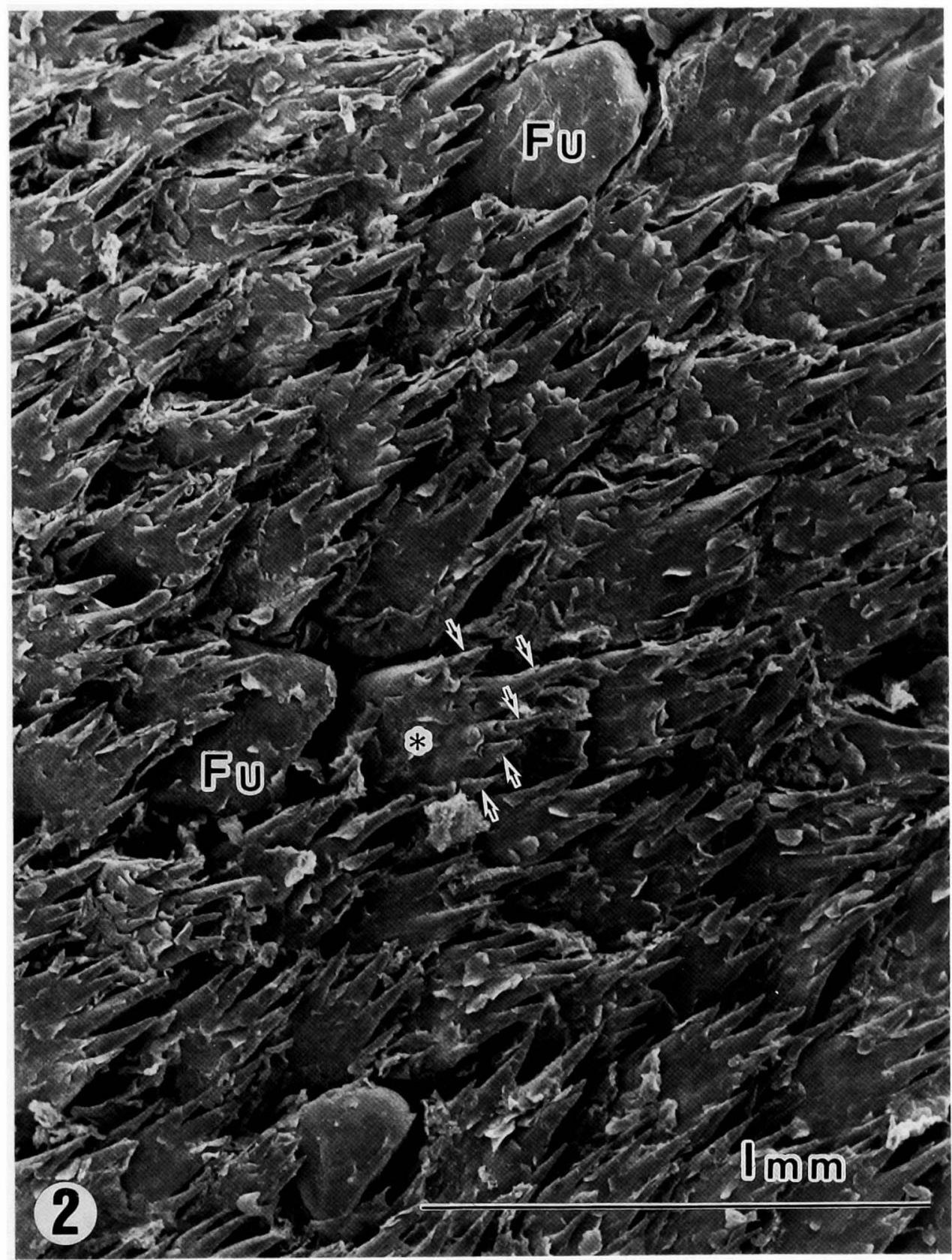

\section{Plate II}

Fig. 2. Dorsal surface of the lingual body. The filiform papilla $(*)$ is larger than that on the lingual apex in size. Arrows $=$ conical processes. $\mathrm{Fu}=$ fungiform papillae. 


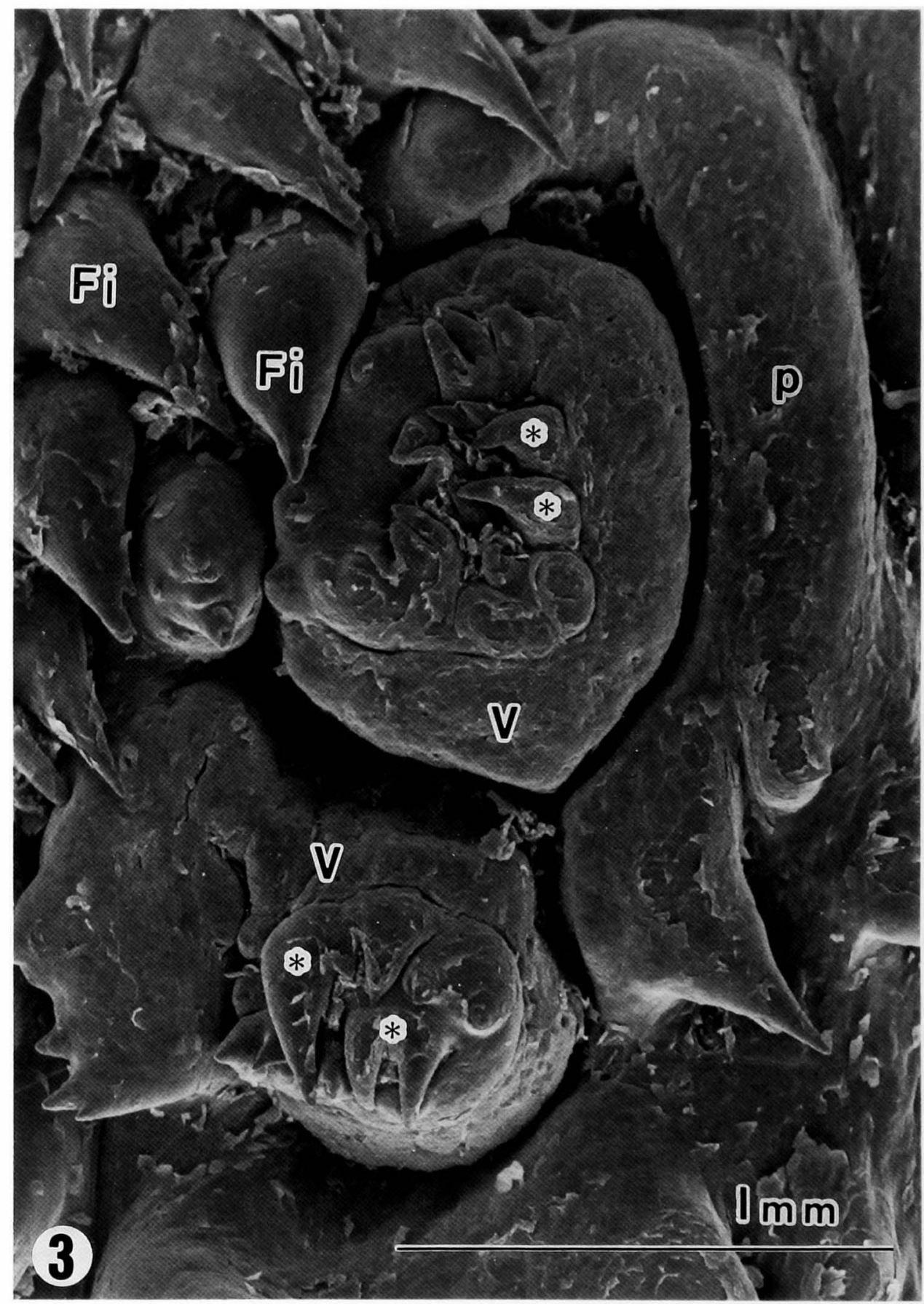

\section{Plate III}

Fig. 3. Posterior end of the lingual body. Two vallate papillae (V) are surrounded by a groove and crescent pad $(\mathrm{P})$. $*=\mathrm{small}$ conical papillae. $\mathrm{Fi}=$ filiform papillae. 